\title{
Computer programs in histopathology record keeping
}

\author{
KV SWETTENHAM, C NICKOLS, CL BERRY \\ From the Department of Morbid Anatomy, The London Hospital, London EI
}

SUMMARY Increasing work loads, changes in the nature of data obtained from biopsies, and the use of laboratory statistics in determining financial provision for pathological services combine to enhance the value of computer generated results and indexing in histopathology. The system described here depends on an indexed file system using the Basic Plus-2 language with a PDP-11 computer and SNOP. Error traps are included. The system is designed for secretarial use, SNOP coding being carried out by medical staff.

The combination of an increasing work load, difficulties in obtaining secretarial staff, an increased call for statistical data to provide the basis for administrative decisions and the natural progression of the subject, have all combined to increase the importance of accurate record keeping in histopathology. Endoscopy, with repeated biopsies from individuals throughout the course of their disease has increased the need for prompt tracing of previous opinions to enable comparisons to be made and clinical research is now dependent on the processing of larger numbers of cases and the examination of more variables than before.

The aim of our project was to write computer programs for use by secretarial staff in histopathology. These would enable them to enter patient details, macroscopical and microscopial data, would compile registers and indices and print reports, with the most economical use of data storage. The basis of the program was the use of the RMS (Record Management Services) file handling system used by the PDP-11 computer (North-East Thames Regional Health Authority).

This facility allows the choice of three types of file organisation: Sequential, Relative, and Indexed. In a Sequential file records are stored one after the other -like the alphabet or an address book, but the file has to be read from the beginning to reach the information required. In a Relative file the position of the records can be found by specifying a relative position in the file; an example of this kind is a block of flats where each flat in the block can be

Accepted for publication 6 May 1981 related to any other flat by its flat number.

The type we chose was an Indexed file, which is constructed so that individual records can be accessed by means of "keys" associated with the data, a faster system for retrieval. An example of this type is a catalogue where numbers are used as codes (keys) to identify the contents. The main disadvantage is that the memory space allocation of the record must be stated at the time of programming. For files in use by more than one person (multiple access), the number of records stored (file size) must be stated and a file of this size created. An "Extend" file size, for single users, allows the file to grow as records are entered, to the maximum size stated at the time of program writing.

We have used multiple and single access systems, which, apart from access details, are identical. They are composed of programs for the entry of departmental and hospital number, patient details, reports, SNOP codes, and the printing out of reports. Specific patient details and the SNOP codes are transferred automatically to a small file to serve as a name, number, and SNOP code index.

Various otk-2r programs are provided for a "Search and Find" operation on data in the small file, which can also be accessed and used independently of the main system.

A file size of 5000 blocks was chosen for both the main and small file. This allows a total of 1300 cases to be stored before the main file is reused and 40000 cases before the small file is reused. The data collected from the main file are kept as printed copy, the data from the small file are transferred to magnetic tape when the file is full. 
Method

THE MAIN FILE

A series of programs were written which would each perform a specified function, allowing individual programs to be changed without interfering with the main structure. The only firm decisions which have to be made are those specified in the "Map" and "Open" statements as these define the characteristics of the files and cannot easily be changed.

The variables and size defined in the "Map" statement for the main file are shown in Table 1.

\section{Table 1 Map statement for the main file}

\author{
Departmental number \\ Hospital record number \\ Date sent \\ Patient's surname and forename \\ Date of birth \\ Sex \\ Consultant \\ Ward \\ A number of lines for macroscopical description \\ Date of typing and initials of secretary \\ Consultants initials (for macroscopical description) \\ A number of lines for microscopical report \\ Five pairs of SNOP codes \\ Date of typing report \\ Consultants initials (for microscopical report) \\ Previous surgical numbers-and a variable code used to open \\ second file
}

A total of 1977 characters

The "keys" defined in the "Open" statement were: Primary-Department number.

Alternate-Patients surname, Forename.

The definition of the departmental number as the primary key allows the data to be accessed for the purpose of updating and printing. The patient's surname and forename defined as alternate keys enables their use for the name-number index program. For the multiple access file, the file size has to be defined in the "Open" statement.

Using these file definitions, the first program, "CLRU" was written, to create the file which the other programs will use. Rerunning the program clears the data from the file.

ENTRY OF DATA

\section{"START"}

This first asks for the departmental number of the patient-typed in at the printer or Visual Display Unit (VDU). All the data are then stored under this primary key. If the "RETURN" key is pressedgiving a "null" answer, the program will automatically close the file and end the program. If not closed the program will continue to ask questionsfor example, date tissue sent, patient's surname and forename, record number, age or date of birth, the consultant and the source of the specimen. As it is essential that this data is correct a "correction" facility is provided during various phases of data entry, reminding the secretary to look back over the data already typed and go back and correct any mistakes. The next stage is macroscopical description, which is allowed 14 lines of 62 characters. Again, a "correction" function is added at the end of the description. With The London Hospital programs the user is given the opportunity to open a second file for additional macroscopical detail, if required.

The third stage of the program allows the date of typing, typists' initials, the initials of the doctor who described the specimen and the initials of the consultant who will be reporting the case to be entered.

The final part of the program is an automatic error trap. If a secretary attempts to store a departmental number that is already in memory, the VDU screen will flash "Entry Error" and again ask for the departmental number. If any other error is found the screen will display a number which indicates the error and the position in the program where it occurred. With all the data typed correctly and checked for mistakes, the data are then put into the file. The machine then goes back to the start of the program to enable further records to be entered. If no more data are to be added the "RETURN" key is pressed and the file is closed.

\section{PRINTING OUT}

"PRINT 1",

This program begins by displaying its function, printing out departmental number and macroscopical data, making it possible to see that the right program has been chosen. The first and last departmental number to be printed are then specified and all data between these two is printed. The copy is then given to the pathologist for microscopical reporting and SNOP coding. This program also incorporates an error trap, if a departmental number is missing the printer will stop and the VDU will flash "Number not found." When all the data has been printed, the printer is automatically switched off and the file closed while the VDU will display "Control returned to VDU" to show that the program has ended. Data may also be displayed on the VDU without printing.

The sheet generated by "PRINT 1" is returned from the pathologist to the secretary who runs "UPDATE" to enter the microscopical report and SNOP codes. This program works in a similar way to those described above first displaying its function, and asking for the first departmental number to 
"update." This number is used as the primary key to find the correct record. An error trap is included.

Having found the record the program then asks for up to five pairs of SNOP codes. If a SNOP code is not entered the VDU will display-"SNOP code not entered, this report will not be printed."

The date of typing and secretary's and pathologist's initials are then entered, an error trap is run and the microscopical report is then entered using 14 lines of 62 characters. A facility for extending the report is available. A further mistake check then occurs; if all is correct the record is then updated.

The program then opens the small file. The primary and two alternate keys remain the same but the Hospital record number and first pair of SNOP codes are added as alternate keys. These data are then stored automatically (file size 65 characters). If more SNOP codes have been used then a further file is opened, these SNOP codes become alternate keys and are again stored automatically. As most records will only have one pair of SNOP codes, the opening of a second file only when there are more than one gives economical use of memory storage (file size 51 characters).

The program then goes back and asks for the next departmental number to update. As with the previous programs, pressing "RETURN" (null entry), causes the program to close all files and end.

The complete report is printed using "PRINT 2" which is closely comparable to "PRINT 1." If the record is found but SNOP codes have not been added, then the VDU displays "No SNOP codes" and the report is not printed. The program then goes on to print the next complete record.

The program prints the report on one sheet of paper $(8 \times 11$ inches $(20 \times 28 \mathrm{~cm}))$ with the departmental number and patient details at the top of the sheet. This is followed by the macroscopical description and the microscopical report, with the SNOP codes, date of typing and space for the pathologist's signature at the end (see Figs 1 and 2).

The paper used in the line printer is 8 inches $(20 \mathrm{~cm})$ wide, tractor fed, continouus sheet, perforated at lengths of 11 inches $(28 \mathrm{~cm})$-which allows for one report per sheet.

Our extended macroscopical and microscopic report results in two sheets with the departmental number and patient details on the top of both sheets. The printed reports are then given to the pathologist to sign before being sent to the ward or becoming part of the departmental records.

\section{Other programs}

These programs are used to deal with departmental enquiries, and with clearing of data from the files.

"MANDY" makes use of the fact that the patient's

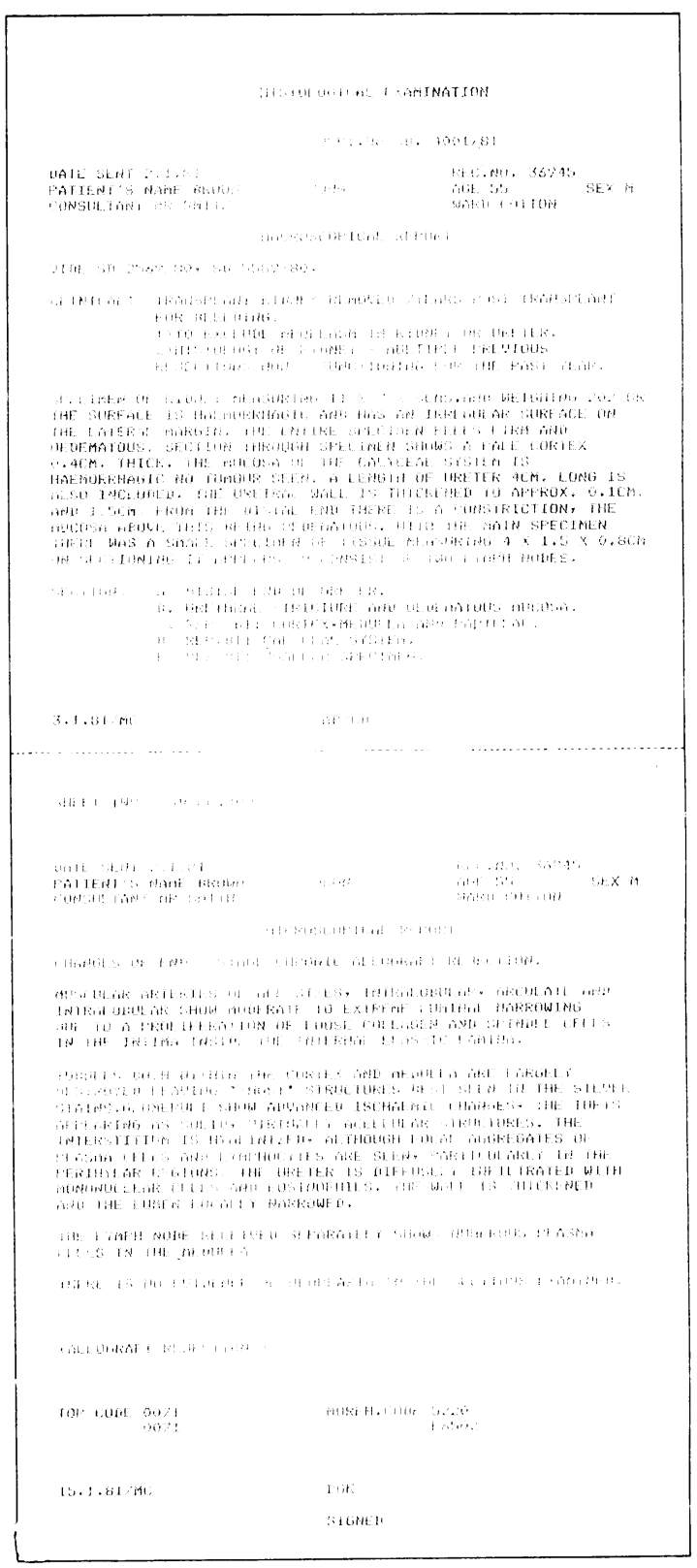

Fig. 1 Double sheet report

name has been defined as an alternate key in the "Open" statement, thus allowing a piogram to be written which will search by name and not departmental number. When an enquiry about a patient is made, the secretaries can enter the name and the computer will return the departmental numbers of 


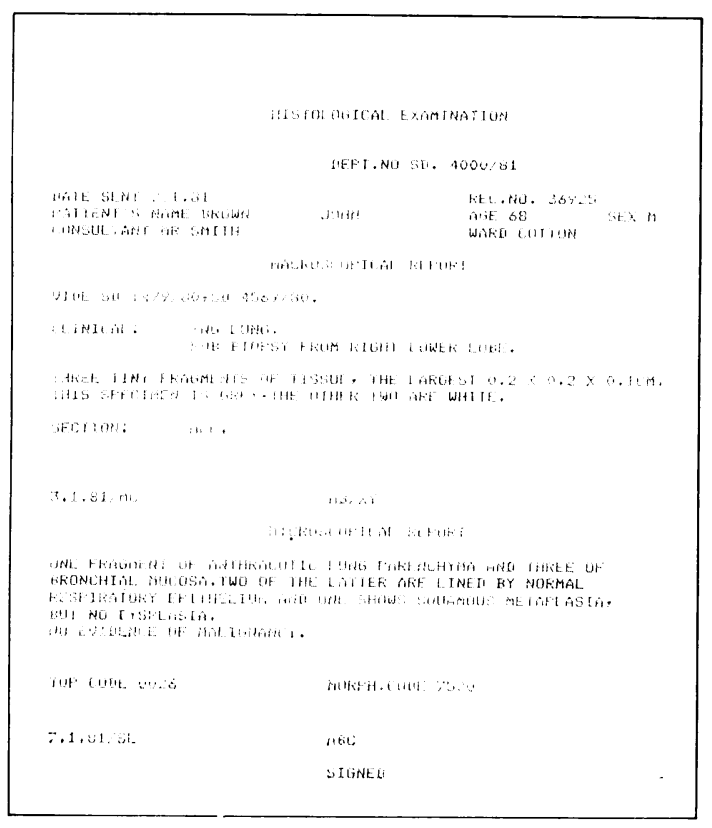

Fig. 2 Single sheet report

the patients on record that match the name. If the hospital record number is known then this can be entered with the name so that a more accurate match can be made. If the patient has had any biopsies within the previous month, these numbers will also be returned, making it possible to choose the report which is relevant, or to read all of them. "MANDY 2" searches the small file which we anticipate will cover 3-4 yr.

"DELETE" will remove one particular record at a time from the main and small files. The program first asks for the departmental number of the record to be deleted, and then displays the patient's data on the VDU enabling the record to be checked. A definite instruction to remove the record must be made before it is deleted.

In order to reuse the main file, existing records have to be deleted to allow further data to be entered. "RECDEL" will display the last departmental number deleted and the date on which this operation was carried out. It then asks for the number of records to delete and the departmental number from which this is to start. The program first attempts to get the record out of the small file-if this operation is successful, it is certain that the specimen has been reported. The program then accesses the main file, gets the record and deletes it. If the record is not found in the small file-that is, is not reported, the main file is accessed and the data are transferred to a file which contains all the non-reported cases. The record in the main file is not deleted and the program continues by getting the next departmental number from the small file. When the program has finished deleting the specified records the last deleted departmental number is automatically stored. The VDU then asks for the date, and these two pieces of information are displayed first when the program is next run.

Data transferred by this program into the "nonreported" file can be accessed using "MANDY" programs described previously. "MANDY" will search the file for a specific departmental number whilst "MANDY 2" will perform a name or departmental number search. A program called "SEQMF" searches the main file sequentially and is similar to "SDSEQ," described in the "Search and Find" section.

"CODEIN" was written to enable missing SNOP codes to be added to the reports. As with "UPDATE" this program also transfers data automatically into the small file.

For a summary of program functions see Table 2.

THE SEARCH AND FIND FILES (SMALL FILE) The small file system may be used in two ways. Data may be fed into it automatically from the main file system or by using a program called "RECORD." The files in the small file system are generated by two short programs called "CLRT" and "CLRV." These are identical to "CLRU," previously described. The primary and alternate keys used are described later.

In both instances the data stored are the same comprising the departmental number, still defined as the primary key, the patient's surname and forename - defined as the first and second alternate keys, the first pair of SNOP codes as the third and fourth alternate keys and the hospital record number as the fifth. The provision of an automatic secondary file allows the storage of a further four pairs of SNOP codes-also defined as alternate keys. It is thus possible to use the small file system as a name, number and disease index automatically generated by the main system or in its own right-data being fed in by the program "RECORD."

This data entry program for the small file begins by asking for the departmental number, then continues by asking questions regarding the patientthe surname, forename, sex, date of birth or age, hospital record number and the first pair of SNOP codes. As with the main file data entry programs a correction facility is available before the program asks if there are any more SNOP codes to be added. If not, then the data are put into the small file and the program returns to the beginning. If there are 
Table 2 Summary of function of programs

\begin{tabular}{|c|c|}
\hline Program & Main file system \\
\hline CLRU & $\begin{array}{l}\text { Primary-generates the main file. } \\
\text { Secondary-Clears the main file of data. }\end{array}$ \\
\hline START & $\begin{array}{l}\text { Enters departmental number, patient details } \\
\text { and the macroscopical description. }\end{array}$ \\
\hline PRINT 1 & $\begin{array}{l}\text { Prints above. Printed copy given to } \\
\text { pathologist. }\end{array}$ \\
\hline UPDATE & $\begin{array}{l}\text { Enters microscopical report and SNOP } \\
\text { codes. Data are automatically transferred to } \\
\text { the small file. }\end{array}$ \\
\hline $\begin{array}{l}\text { PRINT } 2 \\
\text { DELETE }\end{array}$ & $\begin{array}{l}\text { Prints above. Reports signed by pathologist. } \\
\text { Deletes all data entered, with given } \\
\text { departmental number, from the main and } \\
\text { small files. }\end{array}$ \\
\hline MANDY & $\begin{array}{l}\text { Searches main file by name or name plus } \\
\text { hospital number and returns the } \\
\text { departmental number. This will also search } \\
\text { the "non-reported" file. }\end{array}$ \\
\hline RECDEL & $\begin{array}{l}\text { Deletes reported cases from the main file-as } \\
\text { required. }\end{array}$ \\
\hline CODEIN & $\begin{array}{l}\text { Allows SNOP codes to be entered plus } \\
\text { automatic transfer to the small file. }\end{array}$ \\
\hline SEQMF & $\begin{array}{l}\text { Sequentially prints out departmental numbers } \\
\text { and data between two given numbers or only } \\
\text { the missing cases, as required. }\end{array}$ \\
\hline Program & Small file system \\
\hline CLRT & Primary-generates small files. \\
\hline $\begin{array}{l}\text { CLRV } \\
\text { RECORD }\end{array}$ & $\begin{array}{l}\text { Secondary-clears small files of data. } \\
\text { Enters departmental number and patient } \\
\text { details and SNOP codes. }\end{array}$ \\
\hline UPDATE (main file) & As above but by automatic transfer. \\
\hline MANDY 2 & $\begin{array}{l}\text { Searches by name or name plus hospital } \\
\text { number. Returns departmental number. This } \\
\text { will also search the "non-reported" file. }\end{array}$ \\
\hline FIND 1 & $\begin{array}{l}\text { Searches by departmental number, patient's } \\
\text { surname, surname plus record number and } \\
\text { first pair of SNOP codes. }\end{array}$ \\
\hline FIND 2 & $\begin{array}{l}\text { Searches by departmental number, patient's } \\
\text { surname, surname plus hospital record } \\
\text { number, hospital record number, or forename. }\end{array}$ \\
\hline 4 SNOPS & $\begin{array}{l}\text { Searches by Topographical code, } \\
\text { Morphological code or both, in the extra } \\
\text { SNOP file. }\end{array}$ \\
\hline SDSEQ & $\begin{array}{l}\text { Sequential print out of departmental } \\
\text { numbers and data between two given } \\
\text { numbers or only the missing cases, as } \\
\text { required. }\end{array}$ \\
\hline TYPRIT & $\begin{array}{l}\text { Deletes all data entered with a given } \\
\text { departmental number from the small file. }\end{array}$ \\
\hline
\end{tabular}

more SNOP codes, the file for the extra codes is automatically opened, a request for entry is displayed on the VDU. After correction, these are then stored in the second file and the program returns to the beginning. Like all other programs, pressing the "RETURN" key closes the files and ends the run.

The search and find programs are written using a combination of keys. The program entitled "FIND 1 " will access data using the departmental number (primary key) or the patient's surname (alternate key) and the first pair of SNOP codes (alternate keys). For example, entering a given SNOP code will return all the records that match this code. (The SNOP code referred to here can be the Topographical or Morphological code, or both.)
"FIND2" works in a similar way except that it uses different keys for its function. A choice is given to match the records on file with the departmental number, patient's surname, surname and forename, hospital record number or forename alone. If it is not clear which is the surname and which is the forename the program will automatically swop them over and rerun the search.

On both "FIND 1" and "FIND 2" an automatic error trap is incorporated to prevent the file from returning an error when all the records on file have been searched through in order to find the match. The program automatically goes back to ask if another search is required, if it is not, then typing in "NO" or pressing the "RETURN" key will close all the files and end the program.

As the additional SNOP codes have been designated alternate keys, this file may also be accessed to match these extra codes, by a program called "4SNOPS." This will return any match, if found, for any SNOP code entered.

A program is provided to duplicate the function of "PRINT 2" used in the main system. This program, called "SDSEQ" will print the data in the small file sequentially between two given departmental numbers, either on the line printer or the VDU. If the number is not found the number missing will actually be printed. This enables the content of the small file to be rapidly checked, which is particularly useful when the small file is used independently and the data are not generated by the main system.

The last program, "TYPRIT," is used to delete data from the small file. This is necessary when using the small file system alone or when the primary data has been deleted from the main file-that is, when it exceeds 1300 cases. Running this program displays the data requested and a definite statement has to be made before the data are deleted from the file. The program ends by displaying the name of the program used to re-enter the correct data.

\section{Conclusion}

Reading an account of a computer program is seldom other than tedious. The system, in use, is flexible and relieves the secretarial staff of much tedious work, improving their input of data, increasing accuracy and allowing more time for activities often considered to be unimportant, such as the prompt issuing of post-mortem reports. The main difficulty in its use is the establishment of "British Telecom" connections, for the rapidity of machine language is frustrated by the slowness of the telephone.

Requests for reprints to: Professor CL Berry, Department of Morbid Anatomy, The London Hospital Medical College, London E1 1BB, England. 